\title{
Emotional Intelligence: A Model of Pluricentric Emotional Dispersion of Those Involved in Change Management Within a Work ORGanISATION
}

\section{Abstract:}

During work one is striving to contribute towards the modelling of emotions of the employees and the dispersion of their emotions as an inevitable process in the creation of positive emotional contagion upon effective change management within a work organisation. Whilst aiming to point out the vast array of the employees' emotions, the paper provides a broader approach comprising of 11 forms of organisational behaviour which are more or less affected by the emotions of the employees. The focusing of emotional intelligence has been performed through four components: self-awareness, self-management, social awareness and relationship management. Each organisational change results both in positive and negative emotions amongst the employees.
These emotions have been presented in the paper according to different phases of organisational change. It has to be highlighted that one of the most difficult and most complex problems in the management of the employees' emotions during organisational change is not the identification of emotions, but how to enhance positive emotions amongst a proportion of the employees. Subsequently, how to transfer or disperse them towards other members of the working group and the entire work organisation.

\section{Keywords:}

emotions; emotional intelligence; organisational change; emotional dispersion

\section{Author s data:}

1 Sanja, Gutić Martinčić, Assistant, High school of finance and low "Effectus", Zagreb, Irg J. Kennedya 2 , gutic.sanja@gmail.com

International Journal - VALLIS AUREA • Volume 3 • Number 2 • Croatia, December 2017

159.9:331; 001 10.2507/IJVA.3.2.8.41 


\section{Introduction}

Emotional intelligence is a topic that has been increasingly and more frequently arousing interest both of the scientific and professional public within the contemporary management. Emotions are a characteristic that separates humans from animals. Moreover, being innate, emotions continuously accompany human personalities and appear in all everyday life situations, as well as at work. They are powerful drivers of a large number of psychological functions of humans. A wide range of research studies conducted during the last 15-odd vears have provided us with findings which state that emotions and the management of employee emotions can result in productive management of a large number of processes inside business organisations. Emotional intelligence, as a systematic approach to management, is important also in the sphere of change management within business organisations. It is a well-known fact that emotional resistance of employees to organisational change and its implementation is actually one of the most challenging fields. This paper is striving to contribute to modelling of employee emotions and pluricentric emotional dispersion, as an indispensable and productive course of creation of positive emotional epidemics [contagion], which is necessary in effective organisational change management.

\section{Emotions in the workplace and emotional intelligence}

Approaches and classifications of emotions that appear in the workplace show considerable differences. Hence, according to Poggi and Germani, there are five types of emotions: individual emotions, cognitive emotions, emotions of belonging, emotions of independent perception and other emotional conceptions [16]. Kraus expanded the range of emotions that can be considered as crucial at work [10]. These are:

1. Passion, a strong and hardly controllable emotion that incites beliefs, trust, motivation and loyalty amongst employees.

2. Compassion (empathy) as the ability to understand and share feelings with another person. It is a valuable emotion in the building of organisational culture.

3. Loyalty is an emotion for building of fidelity to a person, a job and an organisation.

4. Fury or anger resulting from a perceived injustice, inequality, dishonesty, workplace mobbing.

5. Enthusiasm is defined as impatient intense pleasure focused on a specific interest. As an emotion, it is significant upon inciting creativity and innovativeness amongst employees and upon project management.

6. Doubt and fear are emotions of bipolar character, since they can cause both negative and positive responses. Doubt is a feeling of insecurity.

7. Happiness or a feeling of happiness leads towards positive outcomes in organisational behaviour. It differs from the concept of satisfaction, as satisfaction is an equivalent of happiness.

8. Satisfaction is a state of happiness that is reflected through gratitude and employee loyalty.

9. Curiosity or curiousness is a tendency to become acquainted with something, to explore and learn. It frequently appears as a result of some dissatisfaction. It is an important emotion in creativity management.

10. Ambition, as opposed to curiosity, is an emotion that inspires work. Determination and preparedness for hard work, doing tasks and tackling obstacles are its features.

Robert Plutchik was probably the person that has provided the most comprehensive classification of emotions. He provided the well-known "wheel of 
emotions" which shows that all the emotions originate from six primary emotions, from which secondary and tertiary emotions develop [15] Emotional intelligence, as a product and construct based on emotions, can be defined as a mental ability or a set of mental abilities, which enables recognition, learning, memory and the ability to think. According to Mayer, emotional intelligence is a notion that is on a par with pure intelligence or cognitive ability of an individual [13]. As opposed to him, Bar-on Reuven considers emotional intelligence as a mixed intelligence that comprises of cognitive abilities and personality [1]. On the other hand, Maver et al., defined emotional intelligence as the ability of accurate evaluation and expression of emotions... the ability to approach and generate feelings in order to facilitate the verbalisation of thoughts [13]. Goleman has thus far probably made the most significant contribution in the field of management of emotional intelligence. He perceived emotional intelligence as a mixed intelligence that includes cognitive abilities, as well as a large number of abilities and aspects of personality [9]. Moreover, he focused emotional intelligence through four components: self- awareness, self-management, social awareness and relationship management.

\section{Organisational change and employee emotions}

The question whether organisations need to undergo permanent change in accordance with the requirements in their environment is absolutely not contentious against the backdrop of modern times. It is a fact that nowadays all the organisations that strive to survive and remain competitive need to undergo continuous changes. What they need to focus their energy and knowledge on is the most effective way in which to implement these changes. Each organisational change is a challenge and an opportunity. Furthermore, it can trigger a wide range of positive emotions amongst the employees. Nevertheless, it can also trigger a large number of negative emotions, since people are by nature afraid of the unknown. According to phases in organisational change, these emotions can be illustrated in the way presented in the table hereafter (Table 1).

\begin{tabular}{|c|c|c|}
\hline $\begin{array}{l}\text { A phase of organisational } \\
\text { change }\end{array}$ & $\begin{array}{l}\text { Negative } \\
\text { emotions }\end{array}$ & Approximate orientative meaning of employee emotions \\
\hline \multirow{4}{*}{ Initiating change } & grief & Why are we abandoning the existingstate-of-affairs? \\
\hline & fear & What will happen with me and my job? \\
\hline & doubt & Will I be able to learn the new? \\
\hline & bitterness & Why is the management doing this to us now? \\
\hline \multirow{7}{*}{$\begin{array}{l}\text { Transition onto a new state } \\
\text { of affairs }\end{array}$} & insecurity & In what way will all of this affect me? \\
\hline & rage & Do I need to put in so much effort to master all this? \\
\hline & agitation & Who knows what else I will have to face? \\
\hline & envy & $\begin{array}{l}\text { Why are the others doing better at fitting in into a new } \\
\text { job? }\end{array}$ \\
\hline & contempt & We are only a means for the generation of higher profits \\
\hline & despair & I am a total failure in this new organisation \\
\hline & remorse & $\begin{array}{l}\text { That is just what I needed when I showed such blind } \\
\text { belief in these new changes to the management }\end{array}$ \\
\hline
\end{tabular}

Table 1. Features of the most frequent negative employee emotionsaccording to phases in organisational change

International Journal - VALLIS AUREA • Volume 3 • Number 2 • Croatia, December 2017 159.9:331; 001 10.2507//JVA.3.2.8.41 


\section{Pluricentric emotional dispersion}

The problem of how to enhance and transfer or disperse positive emotions to other members is probably one of the most difficult and the most complex problems during organisational change implementation.The currently available findings point out the ways of dispersing these emotions from individuals to the entire group and work organisation [3]. The term "dispersion" has been used, since emotions are similar to gases: they are hardly visible and have the ability to affect all the people in one place in a specific moment [14]. According to a comprehensive research of the structure of groups undergoing change, a frequent ratio within a group was as follows: $70 \%$ of emotions comprising of fear, $10 \%$ contempt, whilst $20 \%$ curiosity, or positive emotions [4].

Emotional contagion (as it is frequently referred to) is a mechanism of spreading positive emotions from an individual towards all the members of a working group. The basis of this psycho-mechanism is a human, innate inclination to gladly adopt the emotions of other people in one's environment [8]. Why is pluricentric emotional dispersion necessary? What does it mean? Emotional dispersion from one source (centre) that has thus far almost exclusively been implemented frequently does not provide the expected results. That is primarily because people in organisations are a heterogeneous rather than a homogeneous group. Consequently, emotional dispersion from several homogeneous groups brought together into different employee segments [7] is considerably more effective and productive.
Pluricentric emotional dispersion within working groups and organisation as a unit comprises of at least six connected and interdependent phases:

1. In order to achieve emotional dispersion, a specific level of emotional intelligence amongst organisational members needs to be achieved. From the structural aspect it has been shown through four elements: self-awareness, self-management, social awareness and member interaction.

2. Emotional dispersion originates from several centres (sources of positive emotions, individuals, group members]. They have been referred to by using upper-case letters in the picture.

3. Identification of the level and the form of heterogeneity of organisational members and defining of emotional segments.

4. Emotional dispersion in the narrowsense of the word amongst members of a group/organisation.

5. Emotional dispersion achieves a required level of emotional temperature in an organisation. It is required to provide a background for the development and creation of emotional contagion.

6. Emotional dispersion achieves a required level of emotional temperature in an organisation. It is required to provide a background for the development and creation of emotional contagion.

7. Emotional contagion amongst working group members (marked in lower-case letters in the picture) and the organisation as a unit is the final purpose and scope of emotional intelligence management. 

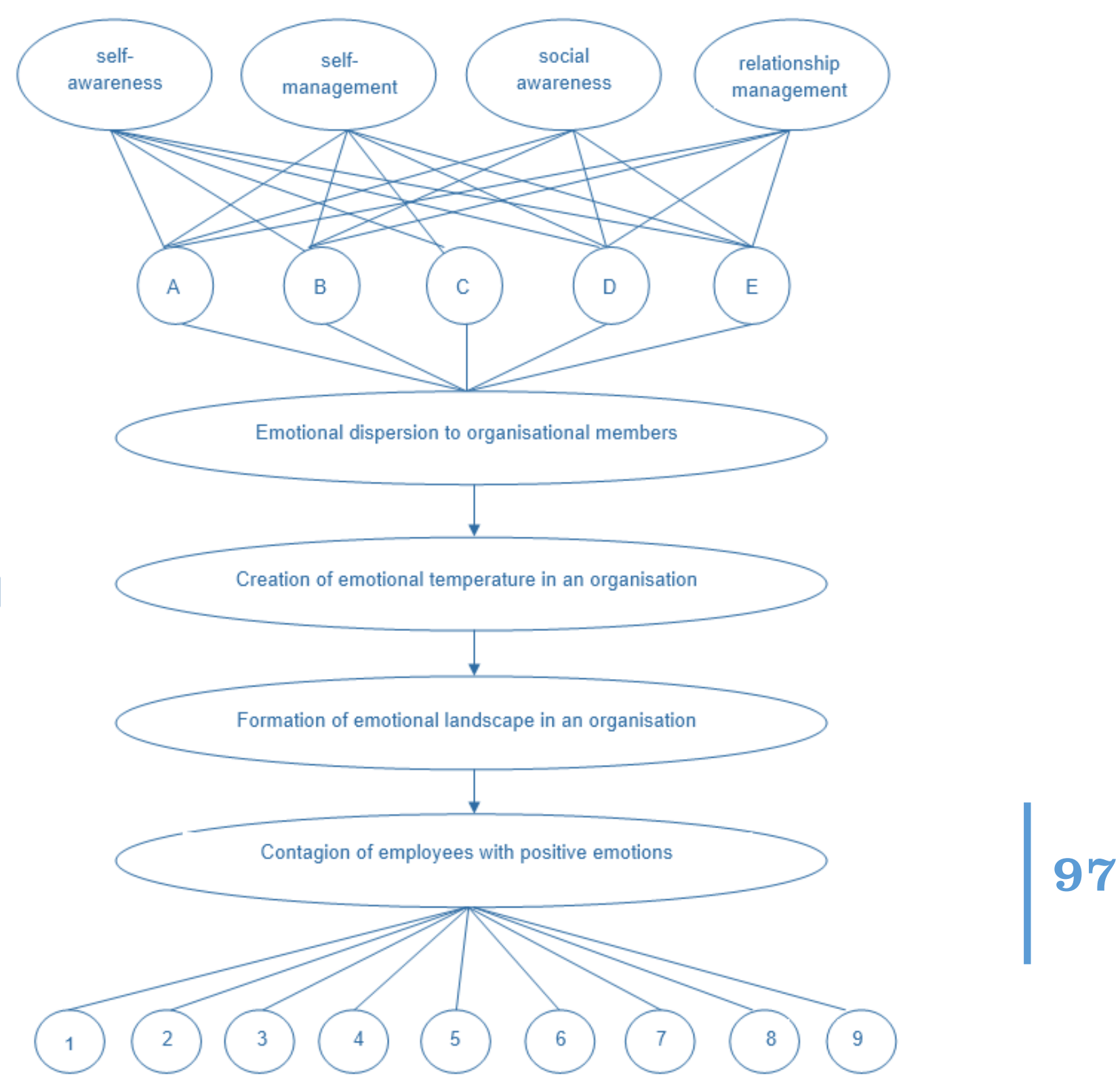

Figure1. Phases of pluricentric dispersion of employee emotions in a business organisation

These phases have been presented in picture 1 .

In order for the model of pluricentric emotional dispersion to function, sources (centres) of dispersion of positive emotions focused on organisational changes need to develop all the four elements of emotional intelligence, as it has been previously stated. In other words, emotional awareness needs to develop. Everyone with developed emotional awareness will be capable of dispersion of positive emotions about organisational change to all organisational members.
Once this dispersion has been achieved, an emotional landscape will be formed in the organisation that will provide a fertile background forthe creation, growth and strengthening of emotions amongst employees concerning change [2]. Contagion of employees with positive emotions arises out of this landscape and it spreads to all the organisational members. The state of emotional contagion is not easy to achieve. Upon initiating organisational changes only a proportion of employees most frequently has positive emotions and emotional flows towards these changes. Most of 
them either do not have them at all or have negative emotions [5]. An increase in positive emotions needs to be achieved through emotional climate prior to emotional dispersion. This is achieved through a wide range of techniques and training sessions intended for identification of emotions. Amongst the proportion of employees who have negative emotions towards organisational changes, additional work will be required, focusing on easing the burden of negative emotions on these employees through their identification and training sessions intended to eliminate such emotions [6]. This has been illustrated in picture 2 .

Identification, strengthening and easing of emotions characterise the phase of initiation of change. Emotional dispersion is typical of a phase of change implementation, whereas emotional contagion is a feature of the phase of cementing (strengthening) of the implemented organisational changes.

Model of pluricentric emotional dispersion in organisations whose objective is greater effectiveness in organisational changes has been presented in picture 3 . It comprises of the following elements:

1. Identification of positive and negative emotions, strengthening of positive and easing of negative emotions of the employees,
2. Creation of emotional temperature in an organisation,

3. Emotional dispersion from four hypothetically placed centres of homogeneous segments of employee emotions,

4. Creation of emotional contagion as the ultimate purpose of emotional intelligence management in business organisations.

The presented model is of theoretical and hypothetical nature and it is intended to provide an explanation of processes and interdependence of effectiveness of changes and impact of employee emotions on these changes.

\section{Implementation of the model}

A large number of reputable international companies have thus far effectively implemented different emotional intelligence models in change management. It is important to mention Avon, American Express, Boeing, Hilton, Honeywell, Johnson \& Johnson, L'Oreal, Motorola and Metlife, to name a few. There is a wide range of advantages to the model of pluricentric emotional dispersion, presented in this work compared with the emotional intelligence models normally implemented thus far. The previously mentioned advantages primarily comprise of:

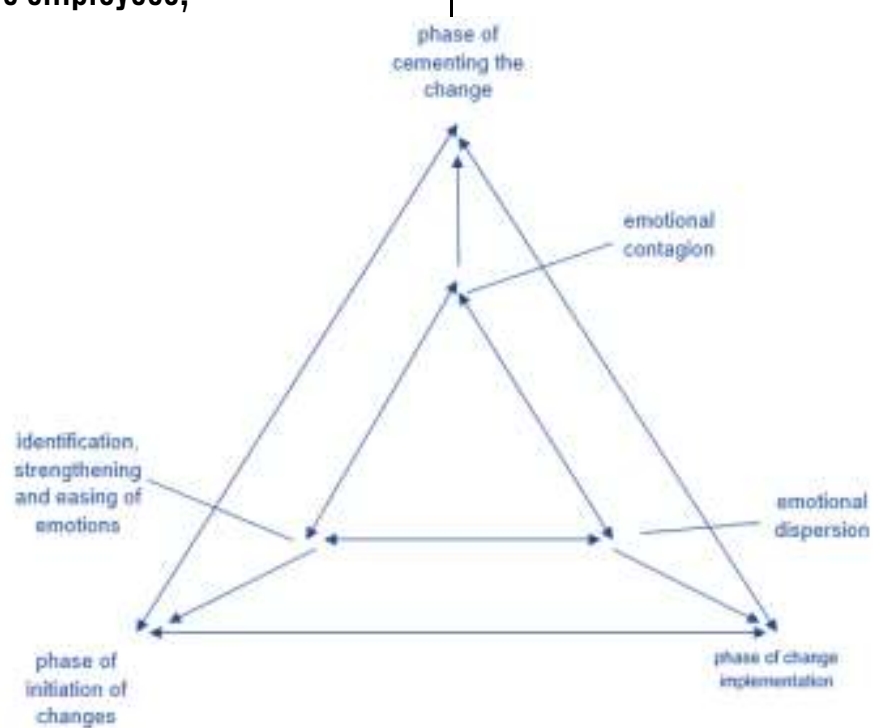

Figure 2. Phases of organisational change and emotional intelligence management 
1. Identification processes of employees are more effective and realistic due to homogeneity of members within the segmented working groups,

2. Transferof emotions from an individual ( individual emotions) to emotions of other members within the group (social emotions) is faster and with a lower perceptual selection.

3. Emotional temperature within working groups, and hence at the organisational level, is reached faster and longer lasting results are achieved.

4. Emotional stability of groups at the organisational level is higher and more reliable.

Nevertheless, upon implementation of the proposed model the following conditions and assumptions need to be considered:

1. Organisations need to have a developed, modern and adequate human resources system [12],

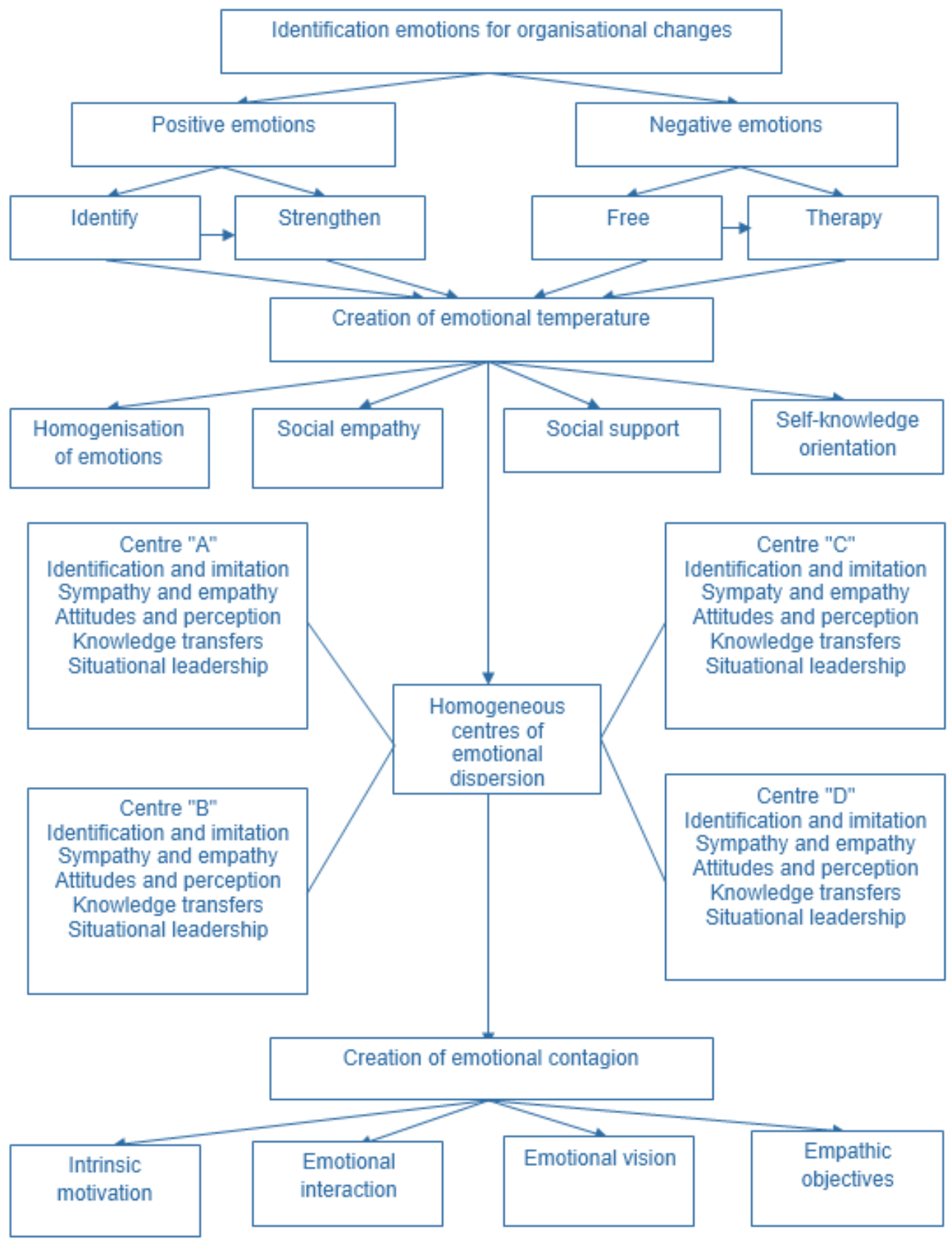

Figure 3. Model of pluricentric emotional dispersion 
2. Management in the organisations that are striving to implement emotional intelligence needs to be adequately trained in this segment, primarily through training programmes on emotional intelligence.

3. Management in the organisations that are striving to implement emotional intelligence needs to be adequately trained in this segment, primarily through training programmes on emotional intelligence.

4. Human resources leadership needs to be based on one of modern models such as transformational Ieadership model [11].

Implementation of the model of pluricentric emotional dispersion is inconceivable without highly educated multidisciplinary teams.

\section{Conclusion}

This paper addresses several issues. It primarily aims to present the value, complexity and importance of employee emotions in business organisations concerning the roles and the assumption of roles by the employees during organisational changes. This is because both theory and practice have thus far pointed out the fact that problems and employee resistance to organisational changes occur primarily within the sphere of negative emotional flows amongst the employees. Management risks and questionability of effective implementation of organisational changes increase substantially in the absence of understanding of these emotions and unless the prerequisites of emotional intelligence management have been adopted. The model of pluricentric emotional dispersion has been presented as a contribution of the author in this paper. The initial idea behind the model is in diversity and heterogeneity of emotions and emotional flows amongst employees. Consequently, accessing emotional intelligence management through segmentation approach or through several homogeneous employee groups is considered effective. The model of implementation of emotional intelligence is primarily based on effectiveness of emotional dispersion from individuals to other working group members. The model proposed in this paper can enable the management to reduce risks upon organisational change, improve the processes and increase the effectiveness of organisational change.

\section{References}

[1] Bar-on, R. [2002). Bar-on emotional quotient inventory [E0-I], Technical Manual, ISBN 978-1-55798949-9, Toronto

[2] Boateng, I.A. \& Agyei, A. [2013). Employee's emotions: a manageable weapon for organizations. International Journal of Human Resource studies, Vol. 3, No 4, (November, 2013), pp 256-267, ISSN 21623058

[3] Brief, A.P. \& Weiss, H.M. [2002). Organizational behavior: affect in the workplace. Annual Review Psychology, Vol 53, No1, (March, 2002), pp 22-54, ISSN 0066-4308

[4] Duffy, M.J. \& Shaw, D. [2000). The salieri syndrome: consequences of envy in groups. Small GroupManagement, Vol. 31, No1, (April, 2000), pp 3-24, ISSN 0022-3514

[5] Feverherm, A.E. \& Rice, C.L. [2002]. Emotional intelligence and team performance: the good, the bad, and the ugly. International Journal of Organizational Analysis, Vol. 10, № 4, (October, 2002), pp 343-352, ISSN 1934-8835

[6] Frye, C.M., Bennet, R. \& Caldwell, S. (2006). Team emotional intelligence and team interpersonal process effectiveness. American Journal of Business, Vol. 21, No 1, (March, 2006), pp 49-57, ISSN $1935-5181$

[7] George, J.M. \& Jones, G.R. [2001). Towards a process model of individual change in 
organizations. Human relations, Vol. 54, (September, 2001), pp 419-444, ISSN $0018-7267$

[8] Gujial, H. \& Ahuja, J. (2011). Impact of emotional intelligence on teamwork- a comparative study of self managed and cross functional teams. International Journal of Multidisciplinary Research, Vol. 1, No 6, (December, 2011], pp 13-31, ISSN 2349-4182, ISSN

[9] Goleman, D. (2000). Leadership that gets results. Harvard Business Review, Vol.78, (September, 2000), pp 98-122, ISSN 0017-8012

[10] Kraus, E. (2014). Ten emotions that belong int he workplace. Annual Review Psychology, Vol 112, № 3, (August, 2014), pp 84-103, ISSN 0066-4308

[11] Leban, W. \& Zulauf, C. (2004). Linking emotional intelligence abilities and leadership styles. Leadership and Organizational Development Journal, Vol. 25, (May, 2004), pp 554-564, ISSN 0143-7739

[12] Mackie, D.M., Devos, I. \& Smith, E.R. (2000). Intergroup emotions: explaining offesnsive action tendencies in a intergroup context. Journal of Personality and Social Psychology, Vol. 79, № 4, (December, 2000), pp 602-618, ISSN 0022-3514

[13] Mayer, J.D., Roberts, R.D. \& Barsade, S.G. (2008). Human abilities: emotional intelligence. Anual Review of Psychology, Vol. 59, (June, 2008), pp 507536, ISSN 0066-4308

[14] Phan, K.L., Wagner, I., Taylor, S.F. \& Liberzon, I. [2002]. Functional neuroanatomy of emotion: a meta-analysis of emotion activation studies in PET and fMRI. Neuroimage, Vol. 16, [ october, 2002], pp 331348, ISSN 1053-8119

[15] Plutchik, R. [2002]. Emotions and life: perspectives from psychology, biology, and evolution, American Psychological Association, ISBN 978-0-415-44042-4, Washington
[16] Poggi, I. \& Germani, M. [2002]. Emotions at work. Journal of Personality and Social Psychology, Vol. 92, No 3, (October, 2002), pp 822-847, ISSN 0022-3514. 